\title{
A Linguagem Científica de Professores de Matemática em Atividade de Formação Continuada
}

\section{The Scientific Language of Mathematics Teachers in Teacher Education Activity}

\author{
Morgana Scheller ${ }^{1}$ \\ Danusa de Lara Bonotto ${ }^{2}$ \\ Zulma Elizabete de Freitas Madruga ${ }^{3}$ \\ José Maria Chamoso-Sánchez ${ }^{4}$
}

\begin{abstract}
Resumo
Esta pesquisa analisa a Linguagem Científica (LC) em textos escritos de professores de matemática em tarefa de formação continuada com Modelagem Matemática (MM). Os dados foram constituídos mediante questionamento a 19 professores que lecionam Matemática nos anos finais do Ensino Fundamental e no Ensino Médio, participantes de projeto de formação continuada. Para analisar o uso e a apropriação de LC pelos professores e o aporte de ideias de sua capacidade linguística, pauta-se em Halliday e Biembengut e avaliam-se: apropriação conceitual, aspectos léxicos, nominalizações e estilo de sequência textual. Os resultados indicam que esses professores, em geral, possuem domínio conceitual de MM. Embora utilizem itens lexicais, termos referenciais e reduzidas metáforas gramaticais, escrevem seus textos com estilos variados, predominando versões narrativizadas de descrição e/ou explicação. Conclui-se que, embora tenha ocorrido elevado nível de apropriação conceitual, possuem reduzido domínio linguístico relativo à LC.
\end{abstract}

Palavras-chave: Formação continuada; Linguagem escrita; Modelagem na Educação.

\section{Abstract}

This research analyzes the Scientific Language (LC) in texts written by math teachers in a teacher education activity with Mathematical Modelling (MM). The data were compiled by questioning 19 teachers who teach mathematics in the final years of elementary and high school, participants in a continuing education project. To analyze the use/appropriation of LC of teachers and the contribution of ideas of their linguistic capacity, it is based on Halliday and Biembengut and evaluates: conceptual appropriation, lexical aspects, nominalizations and style of textual sequence. The results indicate that these teachers, in general, have conceptual mastery of MM. Although they use lexical items, referential terms and reduced grammatical metaphors, they write their texts with varied styles predominating narrative versions of description and/or explanation. It is concluded that although there has been a high level of conceptual appropriation, they have little linguistic mastery of LC.

Keywords: Teacher Education; Written language; Modelling in Education.

\section{Submetido em: 03/12/2018 - Aceito em: 30/12/2019 - Publicado em: 01/09/2020}

${ }^{1}$ Doutora em Educação em Ciências e Matemática pela Pontifícia Universidade Católica do Rio Grande do Sul, Professora no Instituto Federal Catarinense, campus Rio do Sul, Brasil. Email: morganascheller@yahoo.com.br.

2 Doutora em Educação em Ciências e Matemática pela Pontifícia Universidade Católica do Rio Grande do Sul, Professora na Universidade Federal da Fronteira Sul, campus Cerro Largo, Brasil.Email: danusalb@uffs.edu.br.

${ }^{3}$ Doutora em Educação em Ciências e Matemática pela Pontifícia Universidade Católica do Rio Grande do Sul, Professora da Universidade Federal do Recôncavo da Bahia. Email: betefreitas.m@gmail.com.

4 Pós-doutor em Didática da Matemática, docente e pesquisador. Pertence à Faculdade de Educação da Universidade de Salamanca, Espanha.Email: jchamoso@usal.es. 


\section{Introdução}

O processo de ensino e de aprendizagem ocorre por meio da utilização de diferentes linguagens: linguagem verbal e não verbal, comum ou científica. A Linguagem Científica (LC), sistema semiótico caracterizado por sua estrutura densa e complexa materializada nos aspectos léxico-gramaticais e semânticos (Halliday, 1993b; Halliday \& Matthiessen, 2014), contudo, ainda está aquém do que se poderia esperar nos espaços escolares, quer seja na oralidade, quer seja na escrita. Seu domínio, tanto pelo professor quanto pelo estudante é indicativo de desenvolvimento cognitivo, essencial na vida escolar e para a formação e a (re) elaboração do conhecimento. Assim, a orientação do professor é fundamental para que os estudantes se familiarizem com as diferentes formas de linguagem - em especial, a científica - , tanto na oralidade quanto na escrita.

Nos espaços escolares, no entanto, ainda se privilegia a linguagem oral na exposição de conteúdos e na discussão de temas. $\mathrm{O}$ ensino acontece muito mais pela oralidade, com predomínio ascendente pelo professor ao longo dos anos de escolaridade e para transferência do conhecimento (Sutton, 1992). De igual forma, a utilização da escrita destaca-se, sobretudo, como meio de obtenção de resultados avaliativos dos estudantes ao final de um processo, diferentemente do que indicam Hand, Lawrence e Yore (1999), que defendem a utilização de estratégias da escrita para aprender cientificamente ao longo de todo o processo.

Rowell (1997) e Rivard (1994) destacam que a escrita tem sido utilizada mais como meio de comunicação de conhecimentos do que para (re)elaboração desses. Na sala de aula, geralmente seu emprego tem fins distintos: (i) ao professor, é recurso útil nos enunciados de atividades/questões, esquemas ou resumos; (ii) ao estudante, nos registros do processo, e em geral de forma "mecânica", reprodutora, em função da demanda das atividades impostas pelo professor. $\mathrm{O}$ estudante, nesse processo, utiliza mais essa linguagem que o professor, embora, na maior parte do tempo, não a empregue para a arte de argumentar, como defendem Robertson e Graven (2019).

Para Rowell (1997) e Rivard (1994), é fundamental que os professores conheçam as formas de comunicação escrita e medeiem o processo de produção de textos dos estudantes na sala de aula na forma científica; que os orientem a "equilibrar" o estilo da linguagem e as ideias ali expressas, uma vez que as exigências linguísticas na forma oral são diferentes na escrita. Portanto, é preciso propiciar aos estudantes o "transitar" entre a "linguística" mais simples e comum da fala e a escrita, mais elaborada e densa, pois "o uso da escrita é importante para refinar e consolidar essas ideias novas com conhecimentos anteriores. Além disso, a escrita parece aumentar a retenção de conhecimento co-construído com o passar do tempo" (Rivard \& Straw, 2000, p. 566).

Na condução desse processo, de acordo com Driver, Asoko, Leach, Mortimer e Scott (1999) e Fang (2004), professores mais experientes utilizam linguagem de seu domínio para mediar as práticas educativas e oportunizam atividades para a apropriação da LC. Ademais, com seu domínio da linguagem mais elaborada, incentivam os estudantes a incorporá-la na 
realização de tarefas e outras ações, pois pessoas que não entendem o significado potencial de frases nominais prolongadas e complexas, características da LC, não são susceptíveis a usálas efetivamente em sua própria escrita. No entanto, supõe-se que o professor só possa oportunizar tais atividades quando ele mesmo conheça e se expresse na LC. Portanto, professores que, em sua formação e no início do exercício profissional, nunca aprenderam a argumentar, podem sentir-se despreparados para ensinar argumentação e LC (Gabel \& Dreyfus, 2013).

A propósito, acredita-se na necessidade de integrar estratégias mediadas pela escrita nos espaços de formação (continuada) não apenas para propiciar uma atitude mais reflexiva e investigativa sobre a própria prática (Alarcão, 2010; Zabalza, 2004), mas para aprimorar a LC dos estudantes com a utilização da LC nas práticas educativas e favorecer suas aprendizagens, pois, conforme Planas, Arnal-Bailera e García-Honrado (2018), não existem em sala de aula discursos docentes que sejam ideais e, sim, discursos mais favoráveis que outros para produzir e comunicar certas ideias e oportunizar a aprendizagem dos alunos. Afinal, cabe ao professor "ajudar os alunos a aprimorar sua proficiência linguística nos discursos matemáticos necessários, por exemplo, para explicar, raciocinar, argumentar e defender seu pensamento" (Robertson \& Graven, 2019, p. 4).

Diante dessas considerações, a apropriação e o uso de LC pelos professores podem vir a ser um indicativo contributivo para a mediação de práticas educativas oportunizadoras de LC na sala de aula, também no componente curricular de matemática. Isso porque, ao trabalhar com Modelagem Matemática (MM) considerando-a como oportunidade de ensino com pesquisa, o professor medeia o processo de ensino e de aprendizagem utilizando várias formas de linguagens, não apenas a matemática. E o processo culmina com a apresentação de um texto contendo o que foi estudado e discutido para a resolução da situação-problema, a partir do levantamento de dados e informações. Portanto, o estudante deveria argumentar a respeito de suas escolhas e dos resultados (Robertson \& Graven, 2019). Dessa forma, um trabalho com MM pressupõe a utilização não somente da linguagem formal da matemática, mas também de outras linguagens, pois o estudante aprende mais que apenas matemática ele trabalha com Língua Portuguesa, Ciências, Geografia, dentre outros conteúdos (Biembengut, 2014, 2016). Como bem expressa Carvalho (2013, p. 2789), defende-se que "não adianta atividades investigativas nas mãos de professoras sem habilidades necessárias para promoverem a enculturação científica". Sendo assim, é pertinente investigar tais habilidades nos professores que estão discutindo e implementando práticas de MM na sala de aula.

Nossas ideias coadunam com as de Carvalho (2013) e Sasseron e Carvalho (2008) de que são as interações entre os estudantes, e entre professores e estudantes, que devem propiciar condições à argumentação científica. Acredita-se que o trabalho com MM, entendida como método de ensino com pesquisa, segue o mesmo princípio. Porém, em razão de pouco avançar nesse sentido, também é necessário verificar se os professores conseguem tal feito. 
Assim, a linguagem escrita pode revelar a capacidade linguística dos professores, além de caracterizar o estilo/tipo de linguagem que ele incentiva e pretende que seja utilizado por seus estudantes na expressão do processo de MM. A partir das considerações, questionase: Os professores de matemática da Educação Básica, ao expressar seus entendimentos sobre Modelagem (Matemática) na Educação, de que forma utilizam a LC? Tal questão é guia desta pesquisa, que tem como premissa que a linguagem utilizada pelo professor de matemática da Educação Básica, ao expressar/escrever suas concepções sobre determinados conhecimentos, revela sua capacidade linguística em relação à LC, e tal fato poderá ser implicativo na sala de aula, no modo como aceita, promove ou valida a utilização da linguagem escrita de seus estudantes.

Vale afirmar que na revisão preliminar da literatura não se identificaram estudos sobre a LC de professores de matemática em docência. Oliveira et al. (2009) apresentam uma proposta de formação de professores para o ensino da LC com base em investigação, porém, não oferecem dados nem indicam se eles conduzem o ensino e a aprendizagem da forma adequada. E tampouco revelam se eles se expressam de acordo com a proposta. O mesmo foi percebido em Carvalho (2013), que expõe apontamentos de algumas condições de diálogo entre professores e formadores para um ensino que promova a enculturação científica. Esse estudo, uma formação continuada em que os formadores trabalhavam com professores de Matemática da Educação Básica a construção da linguagem científica em quase todos os encontros, pôde aportar, informações sobre como esses professores utilizam a LC, demonstrando assim seu modo de enculturação científica.

Cabe destacar que se defende a formação continuada numa perspectiva de desenvolvimento profissional, o qual implica um movimento contínuo de transformação e constituição do sujeito dentro de um campo profissional específico, de modo que os professores "aprendem e se desenvolvem profissionalmente mediante a participação em diferentes práticas, processos e contextos, intencionais ou não, que promovem a formação ou a melhoria da prática docente" (Fiorentini \& Crecci, 2013, p. 13).

A partir do exposto, na busca por respostas à questão-guia, apresenta-se aqui um recorte de parte dos encontros de formação continuada com professores de matemática, por meio da análise de suas respostas a uma questão proposta após o desenvolvimento de uma oficina pedagógica e o estudo teórico de MM na Educação Matemática, orientados pelos seguintes apontamentos: i) os professores em seus textos demonstram domínio do conceito de MM na Educação? ii) de que modo sua escrita expressa utilização de LC? Sendo assim, a pesquisa objetiva analisar a LC nos textos escritos de professores de matemática em tarefa de formação continuada com MM na Educação.

\section{Marco teórico: Linguagem (Científica)}

A linguagem, a princípio idealizada como meio que remete a pensamento e realidade, tem seu conceito alterado a partir de Linguística Sistêmico-Funcional de Halliday (1993a, 1994, 2001), Halliday e Matthiessen (2014) e Halliday e Hasan (1989). A linguagem é 
entendida como "instrumento" envolvido nas atividades de negociação, construção, organização e reconstrução de experiências humanas. Trata-se de um dos sistemas semióticos que constituem uma cultura. Além de ser condutora de significados, ela é o principal sistema/recurso para produzi-los; permite a seus usuários interagir para coordenar suas atividades e, ao mesmo tempo, refletir sobre suas diferentes interpretações da experiência e compartilhá-las. A significação é codificada na linguagem verbal com o uso de sistema léxico-gramatical, vocabulário e frases (Halliday, 2001).

Sendo assim, Silva (2019) destaca que o professor em sala de aula necessita entender que o novo papel da linguagem vai muito além de um simples modo de transferência de informação e indica que os "estudantes precisam participar de sua aquisição da linguagem científica" (p. 1), sendo esta adquirida mais efetivamente pela problematização e não pela memorização. Cabe ao professor, com sensibilidade, reconhecer como seus alunos estão percebendo essa linguagem. Afinal, Linguagem e Ciência apresentam-se juntas, pois aprender a Ciência é aprender uma linguagem criada para codificar, ampliar e comunicar o conhecimento científico. O que se necessita compreender é que aprender a linguagem especializada da Ciência é o mesmo que aprender Ciência e que "a linguagem é a condição essencial da aprendizagem, o processo pelo qual experiência torna-se conhecimento" (Halliday, 1993a, p. 94). Martin (1993, p. 200, tradução nossa) assim complementa:

na ciência, a linguagem é uma ferramenta fundamental. Ela é usada para classificar, decompor e explicar, e narrar as investigações que formam a base de uma visão de mundo científico. Daí decorre que ser analfabeto na ciência deve ser negado o acesso a um aspecto crucial da sua tecnologia. A ciência não pode ser entendida "em suas próprias palavras". Ela tem evoluído para um uso especial da linguagem, a fim de interpretar o mundo à sua própria maneira, não no senso comum.

Com efeito, a linguagem é um sistema de signos mediante os quais pessoas de uma mesma comunidade/grupo se relacionam, se entendem e se expressam (Halliday, 1993b). Utilizada para comunicação de conteúdos técnicos e/ou científicos, a LC faz utilização de norma linguística adequada para a argumentação, a clareza na exposição e a objetividade nas expressões próprias do tema tratado. Tais características, desenvolvidas historicamente, diferenciam-na do sistema semiótico mais geral: o discurso textual científico é uma construção que possibilita divulgar o conhecimento por meio de linguagem própria, distinta das demais, por características léxicas, sintáticas e pela configuração textual completa. A fim de exemplificar aspectos linguísticos evidenciados em textos científicos, utilizam-se aqui estudos de Halliday (1993b) sobre dificuldades apresentadas por estudantes cuja língua materna é o inglês, ou ainda, por aqueles que aprendem inglês como segunda língua, que são: definições interligadas; taxonomias técnicas; expressões especiais; densidade léxica; ambiguidade sintática; metáfora gramatical e descontinuidade semântica. Já Silva (2019) destaca que o processo de nominalização e a metáfora gramatical, por exemplo, são fontes importantes de dificuldades para a aquisição da linguagem científica.

A LC requer termos técnicos ou expressões para nomear entidades, característicos de uma mesma área/tema ou campo da Ciência, e não devem ser empregados termos da 
linguagem de senso comum. Além disso, a densidade de informações em determinada passagem do texto, a densidade léxica (Fang, 2004, Halliday, 1993b) determina a proporção de itens léxicos com significado real dentro de uma frase, imprimindo a ela alta densidade informacional. Tal densidade pode ser determinada de duas maneiras: (i) número de palavras com significado na frase (Halliday, 1993b); ou (ii) porcentagem de palavras com significado na frase/texto, em relação ao total (Eggins, 1994).

A densidade léxica é um subproduto da metáfora gramatical. Esta ocorre quando processos ou fenômenos (ações, eventos, processos mentais ou relações), normalmente expressos por meio de verbos, são codificados como "coisas ou objetos" e substituídos por substantivos, ocorrendo a substituição de uma classe gramatical por outra. As nominalizações, além de criar termos técnicos e sintetizar/sistematizar detalhadamente informações, permitem relacionar mais do que um processo ou fenômeno em frase única, assim como ocorre com relações causa-efeito. Um exemplo foi ilustrado por Halliday (1993a) com um trecho do texto de Newton Treatise on Optics: "Essas cores indicam uma divergência e separação mútua desses raios heterogêneos por meio de suas refrações desiguais" [ênfase adicionada] (p. 168, tradução nossa). As metáforas também permitem a formação de grupos nominais longos (negrito) e complexos (Halliday, 1993b; Martin, 1993).

Um texto escrito com características de LC, de acordo com Fang (2004, 2006), Halliday (1993a, 1993b), Lemke (1998, 2002) e Mortimer (2011), constitui um texto distante, não envolvente e de difícil leitura e compreensão; não agrada principalmente aos estudantes, que preferem escrever outros tipos de sequências, as "narrativizadas". Por outro lado, na linguagem comum predominam narrativas que relatam eventos lineares e sequenciais, com os verbos no tempo passado. Na LC os processos expressos geralmente por verbos de ação (no tempo presente) ligados por palavras que exprimem relações (ser, simbolizar, possuir, implicar), dão à LC o caráter estrutural, e o resultado são textos encadeados e articulados, que partem de informação inicial e seguem estabelecendo relações entre os grupos nominais. Os textos que emergem então se referem a sequências textuais descritivas, argumentativas ou explicativas 5 .

As sequências textuais, conjunto de palavras que possibilita que um texto possua determinadas características, são entendidas por Bronckart (1999, p. 118), como "unidades estruturais relativamente autônomas, que integram e organizam frases, podem combinar diversas proposições. A organização linear do texto pode ser concebida como o produto da combinação e da articulação de diferentes tipos de sequências". De acordo com Adam (1992), é habitual um texto integrar diversas sequências. Elas correspondem a cinco tipos de "relações macrossemânticas memorizadas por impregnação cultural (pela leitura, escrita e produção de textos) e transformadas em esquema de reconhecimento e de estruturação da

\footnotetext{
${ }^{5}$ A ordem apresentada representa o nível de complexidade da linguagem científica: o descritivo (mais simples), passando pelo argumentativo (com poucas variantes) até o explicativo, que apresenta inúmeros subtipos: causaefeito, enumeração, especificação, resolução de problema. Cada tipo (ou subtipo) representa diferentes operações lógicas que têm lugar no sujeito produtor do texto.
} 
informação textual" (Adam, 2008, p. 204): narrativa, descritiva, argumentativa, explicativa e dialogal (Bronckart, 1999).

\section{Procedimentos Metodológicos}

A pesquisa de natureza qualitativa interpretativa (Bogdan \& Biklen, 2010) foi realizada com um grupo de professores de Matemática em exercício na Educação Básica (Anos Finais do Ensino Fundamental e Ensino Médio). Trata-se de um estudo de caso (Bogdan \& Biklen, 2010; Yin, 2005), pois nele se analisa uma experiência desenvolvida em um contexto específico, que procurou investigar a linguagem científica dos participantes. Participaram do estudo 19 professores de matemática (16 mulheres e 3 homens), com 16,2 anos (em média) de exercício profissional, atuantes na rede estadual de educação. Dos três professores formadores da Universidade, conduziu o processo um dos autores deste texto.

Desde 2015 o grupo destinou espaço para o estudo de Modelagem (MM e Modelagem na Educação), tendência da Educação Matemática considerada como um método de ensino e de pesquisa, cujo foco é o ensino (de Matemática) com pesquisa. Nessa concepção, o estudante é instigado a levantar questões e dados sobre o tema/assunto, formular um problema e suas hipóteses e, posteriormente, formular um modelo matemático para, na etapa final, solucionar as questões levantadas a partir do modelo, avaliando-o em seguida. Os procedimentos envolvidos no processo de MM devem permitir ao estudante aprender matemática a partir de assuntos de outras áreas e, ao mesmo tempo, aprender a fazer pesquisa (Biembengut, 2014, 2016). Esse estudo

oportuniza a cada estudante: entender uma situação e seu respectivo contexto; conhecer as linguagens envolvidas, incluídas as da matemática e/ou de ciências, que lhes permita descrever, representar, resolver uma situação; e interpretar/validar o resultado dentro desse contexto - aprender a arte de modelar, a pesquisar. Permite ainda propiciar ao estudante o gosto e o interesse por alguma área do conhecimento, ao perceber que esses conteúdos então apreendidos lhes valem como fundamentos ou mesmo "meios" importantes [ênfases adicionadas]. (Biembengut, 2016, p. 178)

A formação pautou-se no pressuposto de que a vivência do processo de MM, seguida do estudo teórico e da reflexão sobre a teoria e a prática, possibilita que os professores estejam confiantes para adaptar o processo para o ensino de Matemática e implementá-lo (Scheller, Bonotto \& Biembengut, 2015). Portanto, oportunizou-se a eles aprender por meio de e sobre Modelagem, utilizando-se de vivência do método e aporte teórico, desenvolvidos na perspectiva da reflexão na e para a ação pedagógica.

Nesse contexto, os dados foram obtidos por meio de aplicação de um questionamento aos 19 professores, realizado ao final do quinto encontro de formação sobre Modelagem na Educação, em 2017. A resposta ao questionamento ocorreu individualmente, e na complementação dos instrumentos de coleta de dados utilizaram-se também filmagens e gravações em áudio dos encontros. 
A pretensão desse questionamento, ilustrado na Figura 1, consistiu em oportunizar aos professores espaço para expressão conceitual do processo de Modelagem vivenciado e discutido, além de identificar características da LC reveladas por eles. No texto elaborado ainda se examinaram os significados expressos, destacando-se a formação conceitual e os erros conceituais da tendência. Para isso, analisaram-se os textos em torno do conceito de Modelagem na Educação de Biembengut $(2014,2016)$ e suas três etapas.

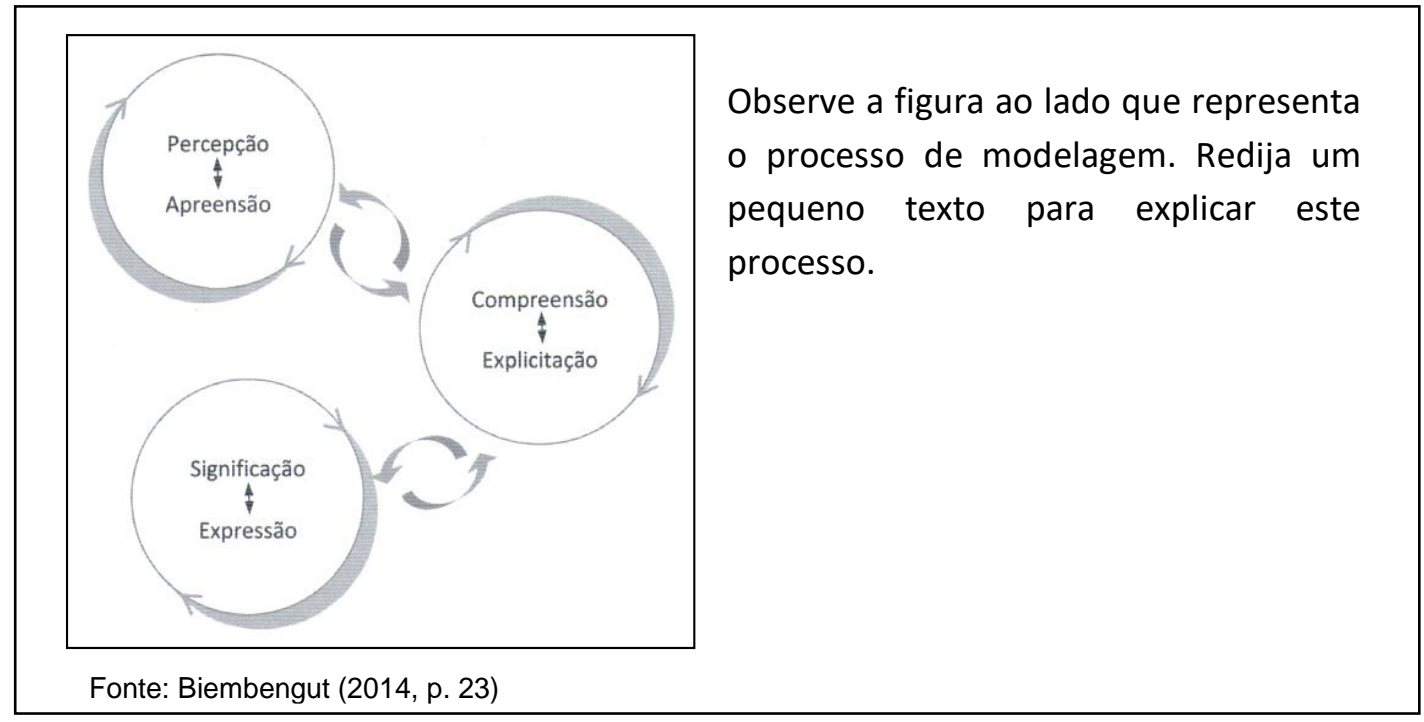

Figura 1 - Questionamento feito aos professores de Matemática participantes da formação continuada Fonte: Elaborado pelos autores

O esquema ilustra o movimento entre as fases da Modelagem, as quais não são disjuntas, mas compõem um movimento constante de "ir e vir". Ressalta-se que o esquema não havia sido visualizado anteriormente pelos professores ou discutido na formação, embora ela tenha subsidiado informações suficientes para uma construção mental do mesmo. Tampouco se discutiu ou trabalhou a linguagem científica, sendo essa uma pretensão futura do projeto.

Para a concretude dos dados utilizou-se a escrita, pois ela pode ser considerada reveladora de um sistema conceitual coerente e significante. Esta pesquisa entende que a escrita revela a expressão do pensamento dos professores sobre o processo de Modelagem percorrido, fundamentado no contexto social em que foi elaborado, e expõe dados característicos do uso e da apropriação de LC de professores de matemática na formação.

Para a análise dos textos considera-se como unidades de análise cada uma das frases (ou partes) que compõem o texto e expressam uma ideia pertencente ao processo. A partir dos pressupostos teóricos de Linguagem, a priori elegeram-se para análise quatro categorias, conforme Quadro 1. A primeira diz respeito ao domínio conceitual de MM - decorrente dos referenciais teóricos - que os professores devem ter, para que possam inserir o método de ensino em sua prática. Já as demais são referentes à LC. Portanto, as categorias emergiram dos referenciais considerados no texto. 
DOI: $10.20396 /$ zet.v28i0.8654144

Quadro 1 - Categorias para avaliação de linguagem científica dos textos elaborados pelos professores

\begin{tabular}{|l|l|}
\hline Categorias & \multicolumn{1}{c|}{ Descrição das categorias } \\
\hline $\begin{array}{l}\text { Apropriação } \\
\text { conceitual }\end{array}$ & Refere-se ao nível de domínio do conceito de Modelagem e das fases do processo. \\
\hline $\begin{array}{l}\text { Aspectos } \\
\text { léxicos - } \\
\text { Termos } \\
\text { referenciais } \\
\text { e }\end{array}$ & $\begin{array}{l}\text { Termos referenciais - expressões ou termos específicos que se referem ao objeto de } \\
\text { estudo - processo de Modelagem na Educação -, os quais são facilmente entendidos e } \\
\text { Densidade }\end{array}$ \\
\cline { 2 - 2 } léxica & $\begin{array}{l}\text { Densidade léxica - refere-se à proporção de palavras que têm significado real dentro de } \\
\text { uma frase. São os substantivos, os adjetivos, a maior parte dos verbos e alguns advérbios } \\
\text { (imprescindíveis para dar significado à frase); excluem-se os verbos auxiliares, as } \\
\text { preposições, os artigos, as conjunções, os pronomes e alguns advérbios. }\end{array}$ \\
\hline $\begin{array}{l}\text { Nominalizações } \\
\text { e Metáforas }\end{array}$ & $\begin{array}{l}\text { Substituição de classe ou estrutura gramatical por outra, para construir argumentos } \\
\text { lógicos, permitindo a formação de processos longos e completos. Para analisá-las, além } \\
\text { de fixar as nominalizações, observam-se os processos verbais - tempo e linguagem } \\
\text { textual do discurso; e a relação entre as partes da oração. }\end{array}$ \\
\hline $\begin{array}{l}\text { Estilo da } \\
\text { composição do } \\
\text { texto / } \\
\text { sequência } \\
\text { textual }\end{array}$ & $\begin{array}{l}\text { Trata-se do conjunto de elementos (palavras) que possibilitam que um texto possua } \\
\text { determinadas características. São esquemas abstratos, superestruturas ou estruturas } \\
\text { globais, que podem se apresentar alternados ou entrelaçados ao longo do texto, e que } \\
\text { envolvem uma série de características linguísticas: narrativa, descritiva, argumentativa, } \\
\text { explicativa e dialogal (Bronckart, 1999). }\end{array}$ \\
\hline
\end{tabular}

Fonte: Baseadas em Halliday (1993b) e Bronckart (1999), exceto a primeira

A partir do estabelecimento dessas categorias, o texto escrito de cada professor, foi lido, codificado como P1, P2, ..., P19 e dividido em partes correspondentes a cada uma das fases da Modelagem (Biembengut, 2014; 2016): 1. ${ }^{a}$ - Percepção e Apreensão; 2. ${ }^{\text {a }}$ Compreensão e Explicitação; 3. ${ }^{a}$ - Significação e Expressão; e as partes dos textos referentes a aspectos gerais do processo. Em seguida, dentro das divisões, identificaram-se as unidades de análise que foram sendo registradas em planilha contendo valores quantitativos de cada item que a compunha. Estes, ao final, foram somados, obtendo-se valores absolutos e, em caso de pertinência, a porcentagem correspondente. As unidades foram organizadas e as relações entre elas foram estabelecidas nas categorias. As compreensões emergentes foram comunicadas em textos descritivos e interpretativos que expressam os sentidos obtidos no processo de análise. As interpretações foram elaboradas com base nos pressupostos teóricos de LC e MM e em estudos já desenvolvidos descritos anteriormente. Para avaliar a LC na escrita dos professores, considera-se que um texto característico desse tipo de linguagem deva: (i) expressar domínio conceitual do tema; (ii) possuir termos referenciais e considerável densidade léxica distribuída harmonicamente ao longo de todo o texto; (iii) conter frases prolongadas e densas resultantes de metáforas gramaticais; (iv) ter prevalência de sequência textual predominante mista, exceto o predomínio narrativo.

\section{Resultados e discussão}

A vivência e a reflexão dos professores sobre o processo de Modelagem (Matemática) viabilizam a reconstrução de conhecimentos sobre possibilidades do fazer científico em sala de aula. A escrita sobre ele ilustra a utilização de linguagem distinta da oralidade. Isso porque, conforme explícito por Halliday (2001) e Vygotsky (1987), a linguagem escrita é 
mais elaborada estruturalmente que a linguagem falada e possibilita pensar, criar/recriar e escrever/reescrever expressões. Portanto, a escrita do processo de Modelagem realizada pelo professor deve conter expressões, termos específicos relativos à Modelagem, de modo que a terminologia (léxico-gramatical) tenha significado no contexto em que está sendo utilizada e no assunto tratado. Os resultados da análise desta escrita estão contemplados a seguir, ao longo das quatro categorias já indicadas.

\section{Apropriação Conceitual}

A análise da escrita dos 19 textos evidencia, conforme Tabela 1, que os conceitos de Modelagem na Educação para os professores são dois: método de pesquisa e método de ensino com pesquisa.

\begin{tabular}{ccc}
\hline \multicolumn{2}{c}{ Tabela 1-Apropriação conceitual dos professores a respeito de Modelagem } \\
\hline Conceitos & Número de textos & $\begin{array}{c}\text { Textos em que há considerações } \\
\text { gerais do Movimento de Modelagem }\end{array}$ \\
\hline $\begin{array}{c}\text { Modelagem como Método de Pesquisa } \\
\text { Modelagem como Método de } \\
\text { Ensino com Pesquisa }\end{array}$ & 10 & 5 \\
Sem domínio conceitual & 6 & 1 \\
\hline
\end{tabular}

Fonte: Elaborada pelos autores

Os protocolos que descrevem Modelagem como método de pesquisa no ensino não fazem referência à área do conhecimento ou à unidade curricular que possa ser utilizada. Já os que se reportam ao processo de Modelagem como método de ensino com pesquisa fazem referência à matemática. Dos professores, 16 evidenciam apropriação conceitual de Modelagem em níveis diferenciados, e apenas em um são inexistentes as considerações sobre a terceira fase do processo. A evidência da Modelagem como método de ensino com pesquisa em seis dos textos deve-se ao fato de que a formação proporciona espaço para adaptação do processo de pesquisa para o "ensino com pesquisa", com a elaboração e a execução de propostas de MM e Modelagem para o Ensino. Isso evidencia a incorporação do conceito decorrente da formação, pelo menos na teoria.

Outro fator importante referente à apropriação conceitual reporta ao significado que esses professores imprimem ao movimento contido no esquema. Cinco dos seis que destacam nos textos considerações do processo como um todo, e não apenas o correspondente a cada fase da Modelagem, conceituam a Modelagem como Método de Pesquisa, conforme ilustram protocolos de P18 e P8, respectivamente: “[...] os vários processos se interrelacionam, é um processo de ir e vir" e "O processo de modelagem envolve etapas semelhante a pesquisa científica". O que pode representar o fato de apenas seis dos professores emitirem considerações do processo como um todo? Duas podem ser as razões: (i) relação entre pensamento e reflexão, funções da linguagem para Vygotsky (1987); (ii) concepção de ensino/currículo.

- $\quad$ Em relação à primeira razão, as considerações indicam que a escrita se inicia (P1 e P18), nestes casos, após análise do esquema e não apenas das partes sequenciais ilustradas 
nele. Ademais, relaciona-se a algo maior do que apenas o ocorrido em cada fase, e vai além do não dito, conforme afirma P8 anteriormente, ao expressar considerações gerais a respeito do processo. Já o protocolo "É um processo que envolve constante reflexão, idas e voltas de pensamento" (P8), registrado ao final do texto, expressa o poder de síntese e argumentação do professor-estudante, após reflexão e expressão do conteúdo do esquema. Isso porque "explicar, ou escrever analiticamente, requer uma posição lógica reflexiva que estimula os estudantes a refinar seu pensamento, aumentando assim seu entendimento do tema estudado" (Oliveira \& Carvalho, 2005, p. 349).

- Em relação à segunda razão, o pouco destaque dado pelos demais ao processo pode ser característico das concepções e das percepções de tais professores: (i) o processo de ensino e de aprendizagem ou de componente curricular fragmentado ou compartimentalizado, de modo que visualizam primeiro as partes que formam um todo. Ao expressarem considerações gerais, os professores dão indícios de concepção de currículo integrado e da matemática "como parte existente no", e não apenas "um constituinte do" currículo. Perceber e expressar apenas fases, e não aspectos e reflexões do processo todo, evidencia uma visão simplista e fragmentada do ensino, o qual seria composto de partes.

Aspectos léxicos - Termos referenciais e densidade léxica

Os termos referenciais também se constituem parte essencial da LC. A análise identifica a presença de termos além daqueles que constam no esquema fornecido aos professores. Os termos iniciais subsidiam a expressão de outros referenciais suportes para a escrita. Como a formação continuada se fundamenta nos preceitos de Modelagem de Biembengut (2014, 2016), embora discutidas outras concepções teóricas, identificam-se os principais referenciais, de acordo com cada uma das fases do movimento, conforme Tabela 2.

Tabela 2 - Principais referenciais nos textos escritos sobre o Movimento entre as fases da MM

\begin{tabular}{ccc}
\hline Fase da Modelagem & Referenciais & Frequência de textos \\
\hline Percepção e & Tema/fato/fenômeno & 14 \\
Apreensão & Problema/problematização/situação-problema & 14 \\
& Familiarização / observação / interação & 10 \\
Compreensão e & Formulação da situação-problema & 10 \\
Explicitação & Hipóteses & 01 \\
& Formulação do Modelo & 10 \\
& Resolução do problema/situação problema & 09 \\
Significação e & Interpretação da solução & 07 \\
Expressão & Validação & 07 \\
& Expressão dos resultados & 03 \\
Processo Geral & Etapa/fase & 04 \\
& Processo de ir e vir / inter-relação entre fases & 03 \\
\hline
\end{tabular}

Fonte: Elaborada pelos autores

De acordo com Fang (2004) e Halliday (1993b), o domínio do vocabulário técnico indica o nível de recurso gramatical necessário para a comunicação precisa e eficaz de ideias científicas e de conhecimento sobre o tema. A presença dos termos deriva da significação 
dada pelos professores a cada uma das fases do processo ou deste na forma geral e eles não são utilizados isoladamente, tampouco explicados nos detalhes, porém contribuem para a expressão do processo, embora a escrita não tenha evidenciado construções taxonômicas complexas.

A ocorrência dos termos referenciais evocados em maior número de textos na primeira fase da MM pode ser representativa da relevância dada pelos professores a essa fase e também da aprendizagem relativa do processo. O contexto da formação pode ser o responsável por esse destaque, uma vez que as outras fases não foram tão explícitas durante os encontros, principalmente a expressão do processo, na terceira fase. A respeito desta, a falta de domínio dos significados dos termos referenciais indica, na visão de Fang (2004), falta de compreensão do texto científico.

A frequência e a presença dos termos referenciais possuem relação com a extensão do texto escrito e do nível de palavras com significados que ele possui (Halliday, 1993b). No caso dos professores, a extensão das produções textuais varia de 33 a 78 palavras $(58,4$ em média), com densidade léxica de 45,2\%, ambas inferiores às da autora da teoria de $\mathrm{MM}$, Biembengut (2014). Isso evidencia que a extensão da escrita dos professores foi reduzida e com densidade baixa, o que caracteriza linguagem pouco estruturada e desprovida de significação do que vem a ser MM.

Tabela 3 - Referenciais léxicos dos textos dos professores e pesquisador/autor da teoria

\begin{tabular}{ccccccccc}
\hline Autor do texto & $\begin{array}{c}\text { N. }{ }^{\text {o de }} \\
\text { frases }\end{array}$ & $\begin{array}{c}\text { Palavras/ } \\
\text { frase }\end{array}$ & $\begin{array}{c}\text { Itens/ } \\
\text { frase }\end{array}$ & Fase 1 & Fase 2 & Fase 3 & Todo & Média \\
\hline Pesquisadora & 11 & 10,3 & 5,6 & 55 & 61,1 & 55,6 & 46,2 & 54 \\
Professores & 3,1 & 18,7 & 8,5 & 45,8 & 45,5 & 44,3 & 45,1 & 45,2 \\
\hline
\end{tabular}

Fonte: Elaborada pelos autores

A análise da Tabela 3 evidencia textos com reduzido número de palavras e, também, de palavras com significado; ambos os aspectos contribuíram para que o movimento fosse expresso de forma sintética, com reduzidos itens léxicos e, consequentemente, pouco denso. A fase do processo de Modelagem mais expressiva em termos quantitativos foi a primeira, apresentando maior quantidade de palavras, itens lexicais e percentual de densidade léxica (20 palavras e 9,2 itens lexicais). Isso indica que, para expressar todo o movimento, utilizam mais espaço (palavras) na escrita com considerações referentes à primeira etapa, reduzindo essa quantidade, até chegar na terceira fase, com $35 \%$ a menos, o que pode ser indício de que a atenção do professor esteja concentrada nas fases que eles mais dominam ou que foram mais expressivas durante a formação.

A curva de redução léxica ao longo da escrita do processo de MM foi oposta à percebida na escrita do pesquisador, o qual destina maior espaço para inferências na terceira fase, etapa esta imprescindível para a expressão do conhecimento e indicativo de aprendizagem. Verifica-se também que a densidade léxica diminui, à medida que o professor e o autor da teoria apresentam exemplificações, uma vez que estas se aproximam mais da 
estrutura da linguagem falada. $O$ fato de a densidade léxica não ser constante, podendo variar de uma parte do texto para outra, foi destacada por Halliday (1993b) em seus estudos.

A estrutura da frase apresenta relação com termos referenciais e densidade léxica e, por consequência, com nominalizações. Para isso, em um texto, de acordo com Eggins (1994), uma frase consiste tipicamente de participantes (substantivos), processos (verbos) e circunstâncias (advérbios e frases proposicionais). Nessas condições, a partir dos estudos de Halliday (1993b) destaca-se que, em textos científicos analisados pelo autor, as frases, em média, contêm 20,3 palavras $^{6}$ (18,6 palavras no inglês) e carga informacional alta e complexa; portanto, frases longas e estruturadas. Diante dessas informações, constata-se nos textos dos professores reduzido número de frases: 3,1 frases longas, enquanto o pesquisador expõe a teoria referente aos movimentos em 11 frases breves. O número de palavras nas frases dos professores, similar aos termos referenciais, também possui caráter descendente no decorrer da escrita. Ademais, as frases dos textos não contemplam a estrutura descrita por Halliday (1993b) e Eggins (1994).

Texto próximo à estrutura descrita por esses autores é o de $\mathrm{P} 6$, com o maior número de frases (cinco no total) dentre todos os textos: 11,6 palavras/frases e 6,2 itens léxicos/frase. Sua densidade é 53,4\%, seguida de P8 (3 frases, 15 palavras e 8,3 itens/frase), com 55,3\%. Esses valores ilustram que, no caso desses professores, um texto bem estruturado e denso requer uso coerente da estrutura gramatical, embora a média de 18,7 palavras/frase esteja próxima dos valores obtidos por Halliday (1993b). Distante desses valores está o texto de P2, que, apesar de possuir quatro frases, apresenta baixo número de referenciais e densidade de $34,3 \%$, valor este distante dos padrões da LC.

A respeito da densidade léxica, de acordo com Halliday (1993b) e Halliday e Matthiessen (2014), na expressão de um mesmo fato/tema/assunto na linguagem oral de senso comum, normalmente, há de dois a três itens léxicos na frase. Quando a linguagem for mais planejada e formal, esse valor sobe; e quando se faz uso da linguagem escrita, o número eleva-se de quatro a seis itens. Já na escrita científica esse valor será mais alto, “cerca de 1013 itens/frase ${ }^{7}$ " (p. 76), pois nesse estilo de linguagem há uma condensação de duas ou mais orações expressas na linguagem falada. Traduzidos para a Língua Portuguesa, a densidade cai de $65 \%$ para $59 \%$, permanecendo ainda alta. A partir dessas considerações, o número da densidade de informação por frase nos textos é bastante reduzido (8,5 itens/frases e 45,2\% de densidade), porém ultrapassa os limites da linguagem comum e da linguagem escrita, descritos por Halliday (1993b) e Halliday e Matthiessen (2014). Nos textos, o número de itens léxicos adequados não implica em garantia de textos característicos da LC, pois não se constituem em textos densos.

\footnotetext{
${ }^{6}$ Número de palavras obtido a partir da tradução do inglês para o português.

${ }^{7}$ Halliday (1993b) destaca que em textos científicos a densidade de informação de fragmentos retirados de outros textos científicos é de 13 (de 22 palavras na frase), 10 (de 14), 13 (de 20) itens léxicos por frase, média de $65 \%$ de densidade. No entanto esses mesmos trechos, traduzidos, têm sua densidade reduzida: 13 (de 26), 10 (de 16) e 13 de (19), ou seja, 59\%. Tal redução já havia sido identificada por Mortimer (1998) e por Braga e Mortimer (2003).
} 
DOI: $10.20396 /$ zet.v28i0.8654144

A seguir, apresentam-se exemplos de fragmentos ilustrativos com: (i) alta densidade $O$ processo de modelagem envolve etapas semelhantes à pesquisa científica (P8). Significação e expressão: interpretação dos resultados (P6); e (ii) baixa densidade - A expressão não nasce do nada, e sim da visualização do que foi realizado (P2). Esse processo todo serve para no final o aluno poder fazer a validação de tudo aquilo que ele mesmo construiu [ênfase adicionada] (P15). De acordo com Halliday (1993b), com o aumento da densidade, as passagens do texto se tornam mais complexas e de difícil leitura e compreensão. Porém, nos textos dos professores que fazem uso de frases longas, a escrita desse modo não garante o referido aumento de densidade e nível de complexidade.

\section{Processos nominais - nominalizações e metáforas}

$\mathrm{Na}$ escrita científica as nominalizações fazem com que se eleve a densidade léxica do texto, ao propiciar aumento no número de processos e no nível de complexidade. Nas metáforas gramaticais, há "substituição de uma classe ou estrutura gramatical por outra" (Halliday, 1993b, p. 79), de modo que possibilita a formação de argumentos lógicos. A análise das nominalizações e das metáforas necessita da observação dos aspectos interrelacionados: os processos verbais - tempo e linguagem textual no discurso; a relação entre partes da oração; e os processos nominais/nominalizações.

Em relação à linguagem textual no discurso, percebem-se nos textos marcas de pessoalidade e impessoalidade (Tabela 4). O grau de intervenção do autor no texto, afastamento ou proximidade, fornece indicativos do estilo de linguagem utilizada.

\begin{tabular}{ccc}
\hline Tabela 4 - Linguagem textual no discurso presente nos textos dos professores \\
\hline Linguagem textual no discurso & N. $^{\circ}$ de textos & Percentual (\%) \\
\hline Pessoal & 3 & 18,75 \\
Impessoal & 6 & 37,5 \\
Mista - predomínio de linguagem pessoal & 3 & 18,75 \\
Mista - predomínio de linguagem & 4 & 25 \\
impessoal & & \\
\hline
\end{tabular}

Fonte: Elaborada pelos autores

A neutralidade, característica da LC, relaciona-se com a impessoalidade no discurso científico (Oliveira \& Queiroz, 2007, 2011). Dos 16 textos, 10 trazem marcas da pessoalidade, percebidas nas construções sintáticas quando os professores utilizam verbos na primeira pessoa do singular ou plural, ao escreverem sobre o processo de Modelagem. $\mathrm{O}$ protocolo de P14 ilustra este tipo de linguagem:

A partir da MM podemos buscar a solução de alguma situação que temos interesse. Então a partir do que temos interesse buscamos tudo que temos de informação e passamos a investigar as possíveis soluções para a questão estudada utilizando qualquer conhecimento ou ferramenta que temos alcance [ênfase adicionada] (P14).

Essa construção, marcada pela pessoalidade, origina textos narrativos (Halliday, 1993b). A reescrita desse fragmento de P14, com adequação às características da LC, poderia 
ser: "A busca da MM por solução de situação problema de interesse parte de informações prévias e segue com a utilização de conhecimento ou ferramentas de alcance". Para Halliday (1993b), tal reescrita demanda da pessoa a reconstrução da imagem mental das palavras, uma vez que processos e acontecimentos são transformados em substantivos. E essa mudança na estrutura gramatical possui resistência e necessita ser aprendida por meio de experiências, por isso a denominação de linguagem como sistema semiótico. Tanto Halliday (1993b) quanto Silva (2019) destacam que esse processo é uma das principais dificuldades para a aquisição da linguagem científica. Portanto, no processo de mediação em aula, o professor precisa ter sensibilidade para reconhecer como os estudantes lidam com esse tipo de linguagem e ajudálos a adquiri-la.

No processo de escrita impessoal prevalecem, ao longo de todo o texto, verbos na terceira pessoa e/ou na voz passiva analítica ou sintética ao longo do texto para garantir a homogeneidade. A voz passiva é útil e, por vezes, necessária estratégia de organização textual (Fang, 2004), pois permite adensar informações depois do verbo, dando um efeito sintático ao final da frase. Além disso, permite que o escritor atinja determinado grau de objetividade e autoridade por não mencionar os autores envolvidos no processo científico. A linguagem contida em seis dos textos contém marcas de impessoalidade, mediante construções sintético-passivas (utilização do pronome se) ou analítico-passivas (utilização de verbo auxiliar ser/ter + particípio do verbo principal), ilustradas, respectivamente, por: (i) "No início define-se algum problema, normalmente amplo" (P7); (ii) "Na etapa percepção e apreensão é o momento de questionamentos referente ao problema que será investigado. A conversa informal em relação ao assunto que será trabalhado” (P13). No entanto, estas construções não implicam no empacotamento de quantidades de informações e processos. Identificam-se textos de linguagem mista, ou seja, escrita do professor oscilando entre expressões relativas à linguagem comum e outras com processo de nominalização decorrente de construções sintético-passivas, como em fragmento do texto de P18: "No processo de percepção, temos a formulação do problema e a familiarização com o assunto a ser modelado" [ênfase adicionada].

Em relação aos processos verbais expressos na terceira pessoa, a LC considera seu uso eficaz para condensar dois processos, percebidos nos textos perante utilização dos verbos de relação ou ligação: é, consiste, representa, segue, valida, envolve e serve. Foram utilizados para definir, classificar, comparar ou caracterizar. De acordo com Halliday (1993a, 1993b) e Fang (2004), os verbos de processos relacionais são recursos de que o escritor faz uso para descrever/explicar os experimentos e estabelecer relações no processo de teorização. A presença desses tipos de verbos tem influência direta nas metáforas gramaticais.

Percebe-se, no entanto, que os professores utilizam na expressão, com frequência: (i) formas compostas de verbos, diferentes das formações analítico-passivas, como "precisamos estudar", "procurar dar significado", "vão compreendendo e dando [...]", "consigo representar"; (ii) verbos no gerúndio - pegando, construindo, percebendo, analisando, compreendendo, validando e expressando; (ii) verbos no infinitivo - conhecer, verificar, 
demonstrar, chegar, encontrar, compreender, descrever e resolver. Essas construções denotam ação contínua referente algo que está, esteve ou estará acontecendo, reforçando processos não finalizados, no caso do emprego do gerúndio; ação propriamente dita, no caso de verbos no infinitivo. Além disso, fazem com que a frase fique com excesso de termos - na maioria, desnecessários. O mesmo é percebido quando o professor utiliza verbos auxiliares ou tempos compostos. Esses casos, de acordo com Halliday (1993b), implicam na redução da densidade léxica e na pobreza de nominalizações.

Quanto às nominalizações, os textos possuem número médio de 7,8 palavras nominalizadas por produção e 2,5 por frase. A primeira fase da modelagem contém a maior quantidade média de nominalizações $(2,5)$, enquanto no outro extremo está a parte dos textos em que os professores se reportam ao processo da Modelagem como um todo. Todas as 124 nominalizações existentes nos textos provêm de verbos e nenhuma de adjetivo ou advérbio. Como esperado, as mais citadas são as do esquema fornecido aos professores, seguidas dos termos referenciais: solução/resultados (7), situação/questionamento/ problematização (6), resolução/resultados (6). Apesar de o esquema oferecer possibilidade para a formação de metáforas gramaticais, essas são restritas e simples.

Dentre os processos nominais identificam-se dois diferentes graus de metáforas, de acordo com Halliday (1993b): relação entre um processo e outro, expressa por conjunção (10); e por verbo de relação/ligação (16). Nesta última, de maior complexidade, não há diferença significativa quando observada a fase da Modelagem em que se situam. O pequeno número de metáforas evidencia, de acordo com Halliday (1993b) e Fang (2004), que a construção de textos metafóricos resulta em texto alienante e nada envolvente, o qual não agrada aos estudantes e, neste caso, nem aos professores, e faz com se produzam versões narrativizadas da ciência (com envolvimento pessoal e respostas emocionais), como em P14. Ao considerar aspectos contidos no processo de formação das metáforas gramaticais, os textos de P8 e P14 ilustram extremos da escrita.

As metáforas constituem importante recurso para descrever/explicar suas experiências e para estabelecer relações argumentativas necessárias para a construção de ideias teóricas. No entanto, dificuldades no domínio desses recursos linguísticos, percebidas nas escritas, impactarão na construção do conhecimento científico e na comunicação eficaz e precisa de informação científica. A presença da pessoalidade no discurso e do restrito número de verbos relacionais e de nominalizações/metáforas é indicativa de reduzido domínio desses recursos linguísticos pelos professores, o que evidencia, de modo geral, dificuldades na comunicação escrita da informação científica relativa aos movimentos da Modelagem.

Estilo da composição do texto - sequência textual

A escrita é importante para o refinamento de ideias anteriores e a consolidação de novas, pois contribui para o aumento da retenção de conhecimento coconstruído com o passar do tempo (Rivard \& Straw, 2000). Por apresentar determinadas características, ela se constitui de sequências textuais variadas. De acordo com os critérios de Bronckart (1999) e 
DOI: $10.20396 /$ zet.v28i0.8654144

Fang (2004, 2006), a maior parte dos textos dos professores é composta por sequências em que predominam explicação ou descrição de modo narrativizado das fases do processo de Modelagem. Os termos utilizados no esquema servem de referentes para utilização de linguagem explicativo-descritiva pelos professores.

Tabela 5 - Estilo textual no discurso presente nos textos dos professores

\begin{tabular}{ccc}
\hline Estilo textual & N. $^{\text {o }}$ de textos & Percentual (\%) \\
\hline Explicação/descrição narrativizada & 7 & 43,75 \\
Descrição & 2 & 12,5 \\
Explicação descritiva & 3 & 18,75 \\
Explicação argumentativa & 4 & 25 \\
\hline
\end{tabular}

Fonte: Elaborada pelos autores

Conforme resultados ilustrados na Tabela 5, o estilo por eles empregado na elaboração de seus textos não é muito diferente daquele utilizado por estudantes da Educação Básica apresentados nos estudos de Silva e Aguiar Junior (2014): predomínio de textos explicativos narrativizados.

Observou-se que na maior parte dos textos (9), os professores se limitam a: (i) narrar/descrever linearmente apenas o referente às três fases da Modelagem; (ii) utilizar linguagem pessoal na voz ativa e verbos auxiliares ou no gerúndio (construindo), que denotam ação ("detectamos", "buscamos", "encontramos”), fatores que contribuem para redução da densidade léxica; (iii) e expor seus conhecimentos a respeito do processo com poucas nominalizações, como no caso de P10, em que não há nenhuma das três existentes, diferente das contidas no esquema fornecido (processo, modelagem e significação); (iv) utilizar escrita pouco clara e objetiva, como no fragmento de P10 ("a seguir"; "sublinhado"), ao escrever sobre a segunda fase do processo de modelagem. Tais características estão próximas da linguagem comum, ilustrada em texto como o de P10, a seguir:

O processo de modelagem segue passos onde inicialmente detectamos o problema chave ou caso a ser trabalhado; sobre esse caso buscamos teses que o expliquem e fizemos teses para ver se nossas ideias são variáveis. Ao final, encontramos uma significação para o caso em questão, construindo um modelo que aproxime o máximo possível às hipóteses levantadas e a realidade [ênfase adicionada] (P10).

Considera-se que em sete textos há predomínio de LC, pois, além de linguagem no estilo explicativo-descritivo e explicativo-argumentativo, apresentam características de impessoalidade marcada pela voz passiva, pela presença de nominalizações de maior grau com uso de verbos de relação entre os processos, termos referenciais de Modelagem e domínio conceitual referente aos movimentos no processo de Modelagem. O texto de P8, anteriormente citado, exemplifica este tipo de linguagem.

Constata-se relação direta entre sequências textuais explicativo-argumentativas, nominalizações de maior grau e expressão de considerações gerais do processo de Modelagem. O mesmo não se verifica quando comparadas com a densidade léxica. Os professores, ao utilizar argumentos em suas explicações, afastam a escrita da linguagem 
pessoal e utilizam reduzidas metáforas gramaticais na expressão conceitual de Modelagem, porém ainda com pouca densidade léxica.

\section{Considerações finais}

Com intuito de analisar, nos escritos de professores de matemática em formação continuada, a utilização de LC, desenvolveu-se este estudo. O foco consistiu em identificar domínio linguístico dos professores por meio da apropriação do conceito de Modelagem. A partir dos resultados, constata-se que: a apropriação conceitual não é homogênea; os professores utilizam-se de vocabulário simples, com pouca complexidade taxonômica; empregam maior número de palavras, termos referenciais e densidade léxica para expressar informações relativas à primeira fase do processo de Modelagem; itens lexicais não significam presença de metáforas gramaticais nos textos, embora eles influenciem nas nominalizações; prevalecem textos narrativizados com explicação e/ou descrição.

Assim, pode-se inferir que a maior parte dos 19 professores de matemática (79\%) deixam transparecer em seus escritos o domínio do conceito de Modelagem. Porém, quando observado seu discurso linguístico, percebe-se que apenas $37 \%$ possuem capacidade linguística em termos de LC, e os demais a possuem de forma reduzida. Nessas condições, partindo da premissa de que o professor só oportuniza atividades para apropriação de LC se ele mesmo conhece e utiliza, entende-se que eles, de modo geral, não são susceptíveis a empregá-la efetivamente na sala de aula, tanto em uso próprio quanto para o incentivo de seus estudantes. Isso pode ser um indicativo das dificuldades na LC por estudantes da Educação Básica.

De acordo com Halliday (1993b) e Fang (2006), a apropriação de uma linguagem se evidencia quando se tem capacidade para ler e escrever na língua própria de uma cultura científica; acessar informações e encampar ações características da cultura científica, desde ler e escrever até formular hipóteses, explicar fenômenos e argumentar. No entanto, no caso desses professores, a pouca familiarização com os recursos gramaticais contribui para que eles apresentem dificuldades na compreensão do conhecimento científico e, por consequência, na escrita.

O exposto torna-se indicativo para orientar novas ações na formação continuada, no contexto específico estudado e, por que não, em outros contextos de formação, pois "um currículo baseado em investigação combinado com um foco explícito na linguagem especializada da ciência, terá o melhor potencial para maximizar a aprendizagem e promover a literacia científica para todos os alunos" (Fang, 2004, p. 345).

Para a mediação do processo educacional e da expressão na LC, professores e estudantes necessitam possuir inicialmente domínio linguístico. Portanto, o professor de matemática deve habilitar-se para tal e também ser "professor de leitura e escrita", pois o conhecimento não é compartimentalizado e a linguagem oral e a escrita são utilizadas em todos os componentes curriculares no processo de ensino e de aprendizagem. A análise, de 
modo geral, revela que os professores não empregam recurso linguístico adequado em sua escrita, o que pode não garantir a seus estudantes condições de alfabetizar-se cientificamente. Ademais, sugere a continuidade deste estudo no que se refere a investigar: i) como o trabalho do professor de Matemática com Modelagem contribui para qualificar a escrita científica dos professores?; e ii) a qualificação da escrita científica dos professores implica na qualificação da escrita científica dos estudantes? Destaca-se que o estudo de Scheller (2017) objetivou identificar como e em que medida a Modelagem contribui para o desenvolvimento da LC de estudantes do Ensino Médio. Entretanto, o olhar para o processo de Modelagem e para a escrita científica dos professores não foi identificado nas pesquisas envolvendo Modelagem e formação (continuada) de professores, conforme mapeamento realizado por Bonotto (2017).

Desse modo, a investigação de tais questões, além de possibilitar a ampliação da temática das pesquisas envolvendo Modelagem e formação (continuada) de professores também contribui para melhorar a linguagem científica desses professores, no contexto específico e estudado e (por que não) em outros contextos de formação.

\section{Referências}

Adam, J. M. (1992). Les textes: types et prototypes. Paris: Nathan.

Adam, J. M. (2008). A linguística textual: introdução à análise textual dos discursos. São Paulo: Cortez.

Alarcão, I. (2010). Professores reflexivos em uma escola reflexiva. São Paulo: Cortez.

Biembengut, M. S. (2014). Modelagem Matemática no Ensino Fundamental. Blumenau: EdiFurb.

Biembengut, M. S. (2016). Modelagem na Educação Matemática e na ciência. São Paulo: Livraria da Física.

Bogdan, R. C., \& Biklen, S. K. (2010). Investigação qualitativa em educação: uma introdução à teoria e aos métodos. Lisboa: Porto Editora.

Bonotto, D. L. (2017). (Re)configurações do agir modelagem na formação continuada do professor de Matemática da Educação Básica. Tese de Doutorado em Educação em Ciências e Matemática. Porto Alegre: Pontifícia Universidade Católica do Rio Grande do Sul.

Braga, S. A. M., \& Mortimer, E. F. (2003). Elementos do gênero de discurso científico no texto de Biologia do livro didático de Ciências. Anais do IV ENPEC (pp. 1-12). Bauru: Encontro Nacional de Pesquisa em Educação em Ciências. Retirado em 02 de janeiro, 2020, de http://abrapecnet.org.br/enpec/iv-enpec/orais/ORAL069.pdf

Bronckart, J. P. (1999). Atividade de linguagem, textos e discursos - por um interacionismo sócio-discursivo. São Paulo: Educ.

Carvalho, A. M. P. (2013). Formação de professores de ciências: duas epistemologias em debate. Enseñanza de las Ciencias: Revista de investigación y experiencias didácticas [online] (pp. 2784-2790), n. Extra do IX Congresso Internacional sobre Investigação en 
DOI: $10.20396 /$ zet.v28i0.8654144

Didáctica de las Ciencias. Retirado em 02 de janeiro, 2020, de: https://www.raco.cat/index.php/Ensenanza/article/view/308069

Driver, R., Asoko, H., Leach, J., Mortimer, E., \& Scott, P. (1999). Construindo conhecimento científico na escola. Química Nova na Escola, 9, 31-40.

Eggins, S. (1994). An introduction to systemic functional linguistics. London: Pinter.

Fang, Z. (2004). Scientific literacy: A systemic functional linguistcs perspective. Science Education, 89, 335-347. https://doi.org/10.1002/sce.20050

Fang, Z. (2006). The language demands of science reading in Middle School. Journal of Science Education. International University of Florida, USA, 28(5), 491-520.

Fiorentini, D., \& Crecci, V. (2013). Desenvolvimento profissional docente: um termo guardachuva ou um novo sentido à formação? Formação Docente - Revista Brasileira de Pesquisa sobre Formação de Professores, 5(8), 11-23.

Gabel, M., \& Dreyfus, T. (2013). O fluxo de prova: o exemplo do algoritmo euclidiano. In A. Lindmeier, \& A. Heinze (Eds.), Proceedings da $37^{a}$ Conferência do Grupo Internacional de Psicologia da Educação Matemática (pp. 321-328). Kiel, Alemanha: PME.

Halliday, M. A. K. (1993a). Towards a language-based theory of learning. Linguistics and Education, (5), 93-116. https://doi.org/10.1016/0898-5898(93)90026-7.

Halliday, M. A. K. (1993b). Some grammatical problems in scientific English. In M. A. K. Halliday, \& J. R. Martin, Writing science: literacy and discursive power (pp. 69-85). Pittsburgh: University of Pittsburgh Press.

Halliday, M. A. K. (1994). An introduction to functional grammar. London: Edward Arnold.

Halliday, M. A. K. (2001). El lenguaje como semiótica social - la interpretación social del lenguaje y del significado. Santafé de Bogotá, Colômbia: Fondo de Cultura Econômica.

Halliday, M. A. K., \& Hasan, R. (1989). Language, context, and text: aspects of language in a social-semiotic perspective. Oxford: Oxford University Press.

Halliday, M. A. K., \& Matthiessen, M. I. M. (2014). Introduction to functional grammar. New York: Routledge.

Hand, B. M., Lawrence, C., \& Yore, L. D. (1999). A writing in science framework designed to enhance science literacy. International Journal of Science Education, 21(10), 10121035 .

Lemke, J. L. (1998). Multiplying meaning: visual and verbal semiotics in scientific text. In J. Martin, \& R. Veel (Eds.), Reading science (pp. 87-113). Londres: Routledge.

Lemke, J. L. (2002). Mathematics in the middle: measure, picture, gesture, sign, and word. In M. Anderson et al. (Eds.), Educational perspectives on mathematics as semiosis: from thinking to interpreting to knowing (pp. 215-234). Ottawa: Legas Publishing.

Martin, J. R. (1993). Literacy in science: Learning to handle text as tecnology. In M. A. K. Halliday, \& J. R. Martin, Writing science: literacy and discursive power (pp. 166-202). Pittsburgh: University of Pittsburgh Press. 
Mortimer, E. F. (1998). Sobre chamas e cristais: a linguagem cotidiana, a linguagem científica e o ensino de Ciências. In A. Chassot, \& R. J. Oliveira, Ciência, ética e cultura na educação (pp. 99-118). São Leopoldo: UNISINOS.

Mortimer, E. F. (2011). Linguagem e formação de conceitos no ensino de Ciências. Belo Horizonte: Editora UFMG.

Oliveira, C. M. A. de, \& Carvalho, A. M. P. de. (2005). Escrevendo em aulas de Ciências. Ciência \& Educação, 11(3), 347-366. https://dx.doi.org/10.1590/S1516$\underline{73132005000300002}$

Oliveira, J. R. S., \& Queiroz, S. L. (2007). Comunicação e linguagem científica: guia para estudantes de Química. Campinas: Átomo.

Oliveira, J. R. S., \& Queiroz, S. L. (2011). A retórica da linguagem científica em atividades didáticas no ensino superior de Química. Alexandria: Revista de Educação em Ciência e Tecnologia, 4(1), 89-115. Recuperado de https://periodicos.ufsc.br/index.php/alexandria/article/view/37548

Oliveira, T., Freire, A., Carvalho, C., Azevedo, M., Freire, S., \& Baptista, M. (2009). Compreendendo a aprendizagem da linguagem científica na formação de professores de ciências. Educar em Revista, 25(34), 19-33. Recuperado de https://revistas.ufpr.br/educar/article/view/16506

Planas, N., Arnal-Bailera, A., \& García-Honrado, I. (2018). El discurso matemático del profesor: ¿Cómo se produce en clase y cómo se puede investigar?. Enseñanza de las Ciencias. Revista de Investigación y Experiencias Didácticas, 36(1), 45-60. https://doi.org/10.5565/rev/ensciencias.2240

Rivard, L. P. (1994). A review of writing to learn in science: Implications for practice and research. Journal of Research in Science Teaching, 31(9), 969-983.

Rivard, L. P., \& Straw, S. B. (2000). The effect of talk and writing on learning science. An exploratory study. Science Education, 84(5), 566-593.

Robertson, S., \& Graven, M. (2019). Language as an including or excluding factor in mathematics teaching and learning. Mathematics Education Research Journal doi: 10.1007 / s13394-019-00302-0

Rowell, P. M. (1997). Learning in school science. The promises and practices of writing. Studies in Science Education, 30, 19-56.

Sasseron, L. H., \& Carvalho, A. M. P. (2008). Almejando a alfabetização científica no ensino fundamental: a proposição e a procura de indicadores do processo. Investigações no Ensino de Ciências, 13(3), 33-352.

Scheller, M. (2017). Modelagem e linguagem científica no ensino médio. Tese de Doutorado em Educação em Ciências e Matemática. Porto Alegre: Pontifícia Universidade Católica do Rio Grande do Sul.

Scheller, M., Bonotto, D., \& Biembengut, M. S. (2015). Formação continuada e Modelagem: percepções de professores. Educação Matemática em Revista, 20(46), 16-24. 
DOI: $10.20396 /$ zet.v28i0.8654144

Silva, F. C. (2019). Linguagem e o processo de ensino e aprendizagem em Química: leituras contemporâneas de Vigotski apoiadas por Tomasello. Revista Eletrônica de Educação. Ahead of print. 1-14. http://dx.doi.org/10.14244/198271992765

Silva, N. S., \& Aguiar Junior, O. G. (2014). A estrutura composicional dos textos de estudantes sobre ciclos de materiais: evidências de uso e apropriação da linguagem científica. Ciência \& Educação, 20(4), 801-816.

Sutton, C. (1992). Words, science and learning. London: Open University Press.

Vigotsky, L. S. (1987). Pensamento e linguagem. São Paulo: Martins Fontes.

Yin, R. K. (2005). Estudo de caso: planejamento e métodos. Porto Alegre: Bookman.

Zabalza, M. A. (2004). Diários de aula: um instrumento de pesquisa e desenvolvimento profissional. Porto Alegre: Artmed. 